\section{Conversion of Salicylic Acid to Gentisic Acid and o-Pyrocatechuic Acid, all Labelled with Carbon-14, in Plants}

MeTHyL salicylate has been found to occur both in the free state $e^{1}$ and as the aglycone of a primeveroside, gaultherin ${ }^{2}$ in Gaultheria procumbens L. (Ericaceæ).

Although it has been shown that salicylic acid gives rise to gentisic (2,5-dihydroxybenzoic) acid in animal tissues ${ }^{3}$ and micro-organisms ${ }^{4}$, little is known about its metabolism in plants. By means of paper chromatography, Griffiths ${ }^{5}$ has shown recently that gentisic acid is widely distributed in higher plants. The fact that both salicylic and gentisic acids occur together in some species prompted us to study the relationship between these two acids.

We have found that when earboxyl-labelled salicylic acid ${ }^{-14} \mathrm{C}$ is administered to plants, it is converted to gentisic and o-pyrocatechuic acids (possibly in the form of glycocides). The methods of administering the compound and extracting the plant material have already been described ${ }^{6}$. The ethanol extracts were acid hydrolysed, continuously extracted with ether, taken into 5 per cent sodium carbonate, then re-extracted with ether after acidification. The final ether extracts were evaporated to dryness at room temperature and the residue dissolved in 80 per cent ethanol and chromatographed on Whatman No. I filter paper using the organic layer of a mixture of $(6: 7: 3)$ benzene:acetic acid:water for the first direction and $(10: 1: 200)$ sodium formate: formic acid:water for the second. The chromatograms were autoradiographed and radioactive determinations were carried out by direct counting on the paper using a thin end window Geiger-Müller tube attached to a scaler.

Salicylic acid-14 $\mathrm{C}$ was also administered to leaves of 5-day-old wheat seedlings, mature leaves of Rhododendron sp. and of Lotus arabicus, and the material analysed in the same way. The results are shown in Table 1. No other acids apart from salicylic, gentisic and o-pyrocatechuic acids were found to be radioactive in any of these extracts. Table 1. DISTRIBITION OF RADIOACTIVITY IN PHENOLIC ACIDS OF
LEAVES OF VARIOUS PIANTS FED WITA SALICYLIC ACID ${ }^{2 *} \mathrm{C}$
Plant

Gaultheria

procumbens

Lhododendron sp.

Lotus arabieus

Thatcher
Percent Radioactivity

Gentisic o-Pyrocatechuic Salicylic

Gentisic and o-pyrocatechuic acids were identified by the isolation of small amounts from the leaves of Gaultheria procumbens. They were located by their fluorescence in ultra-violet light and by colour reactions with diazotized $p$-nitroaniline, diazotized sulphanilic acid and 1 per cent ferric chloride. $p$-Pyrocatechuic acid was crystallized from benzeneether and recrystallized from hot water. It decomposed at $204-206^{\circ} \mathrm{C}$. (uncorrected). Mixing with an authentic sample of 2, 3-dihydroxybenzoic acid did not lower the melting point. Infra-red spectra of the isolated acid and authentic o-pyrocatechuic acid were identical. Gentisic acid was erystallized in the same way as o-pyrocatechuic acid; it melted at $201-202^{\circ} \mathrm{C}$. (uncorrected).

By means of chromatography, o-pyrocatechuic acid was also found to occur in acid hydrolysates of ethanolic leaf extracts of Rhododendron sp., Azalea sp.,
Erica carnea, Vinca rosea, V. minor and $V$. majar This acid has been reported previously to occur in Populus balsamifera ${ }^{7}$ and as a glucoside in Vinca minor ${ }^{8}$. The identification of $o$-pyrocatechuic acid in five genera of the Ericacer suggests that it may be of widespread occurrence in this family.

We have found, by means of paper chromatography, that acid hydrolysates of 30 species analysed for phenolic acids contained gentisic acid in almost every case, whereas salicylic acid was confined to a few species. However, the demonstration that gentisic acid is readily synthesized from salicylic acid in four different species including a monocotyledon suggests that salicylic acid is a common metabolite of plants. It is an interesting fact that the wheat plant which contains none of these acids in a free or bound form is capable of converting salicylic to gentisic and $o$-pyrocatechuic acids.

While protocatechuic $(3,4$-dihydroxybenzoic) acid has been shown to be formed from shikimic acid ${ }^{9}$, the precursors of the ortho-hydroxybenzoic acids are not known. We have found that when carboxyl. labelled benzoic acid-14 $\mathrm{C}$ is administered to plants, salicylic, gentisic, o-pyrocatechuic and $p$-hydroxybenzoic acids are formed. This problem is under investigation.

We thank the National Research Council of Canada for financial support of this work. We wish to thank also the World University Service of Canada for the award of a scholarship to one of us (R.K.I.). Dr. Zacharius of the Zoology Department of MeGill University kindly prepared the infra-red spectra.

Ragai K. Ibrahim G. H. N. Towers

\author{
Botany Department, \\ McGill University, \\ Montreal 2, Canada. \\ Aug. 31. \\ 1 Procter, W., Amer. J. Pharm., 15, 241 (1843). \\ 2 Cahours, A., Annalen, 48, 60 (1843). \\ ${ }^{3}$ Lutwak-Mann, C., Biochem. J., 37, 246 (1943) \\ Walker, N., Biochem. J., 52, 23 (1952). \\ - Hutchinson, A., Roy, C., and Towers, G. H. N., Nature, 181, 841 \\ (1958). \\ Goris, A., and Canal, H., Bull. Soc. Chim, France, 5, 1982 (1936). \\ " Goris, A., and Canal, H., Bull. Soc. Chim. France, 5, 1982 (1936). \\ ' Gross, S. R., J. Biol. Chem., 233, 1146 (1948).
}

\section{PHYSIOLOGY}

\section{Effect of Jet Aircraft Noise on Hearing}

For a long time the hearing of personnel in the Services has been endangered by the noise of gunfire and its deafening effects are well known. Next to gunfire, the modern turbo-jet engine is probably the source of the most intense noise to which large numbers of men are being exposed at present. Various attempts have been made to detect any permanent deterioration in hearing resulting from jet noise but, until recently, no significant changes have been found. Whereas the less intense noise of piston-engined aireraft produces the typical loss of hearing acuity of acoustic trauma which appears first in the region of $4 \mathrm{kc} . / \mathrm{s}$, this form of defect has not been evident with exposure to jet noise.

Under existing conditions with jet aireraft, it is no longer the men who fly the aircraft who are subjected to the greatest noise but the attendant ground staff. Those in the worst situation are the men employed 